Palestra

\title{
CRISIS AMBIENTAL - CRISIS CIVILIZATORIA: EL GIRO AMBIENTAL DE LO HUMANO EN TIEMPOS DE CRISIS CIVILIZATORIA
}

Palestra realizada em 29/10/2013

Local: Instituto de Filosofia, Sociologia e Política, Sala 309, 30 andar

\author{
Ana Patricia Noguera de Echeverri, $\mathrm{PhD}$ \\ Grupo de Pensamiento Ambiental \\ Universidad Nacional Sede Manizales
}

\begin{abstract}
*A mi amado hijo Darío, por su amor infinito a la vida. In memoriam (19772013).
\end{abstract}

Gracias infinitas por esta bella invitación. Es un sentimiento profundo que me ha permitido pensar en la urgencia de un giro profundo del pensamiento sobre lo Humano hoy. Inevitable no pensar en este giro, desde el Pensamiento Ambiental, que ha sido mi lugar desde hace veintitrés años. Este lugar maravilloso emergente de la preocupación por pensar lo ambiental de otra manera, que inauguró en Colombia el Filósofo, Historiador, y Humanista Augusto Angel Maya. Este lugar llamado Pensamiento Ambiental Alternativo se aleja, críticamente, de un concepto de lo humano por fuera de la naturaleza y de un concepto de naturaleza como recurso, e introduce con la fuerza del pensar lo más profundo: la vida y lo vivo, al humano en la naturaleza y a la naturaleza en lo humano, en una disolución urgente y necesaria para que la vida continúe expandiéndose como cultura, es decir, en labor de arte.

El Pensamiento Ambiental se ocupa entonces de la vida y de lo vivo, no en la reducción biologicista y economicista elaborada por el ambientalismo oficiante, sino en la expansión compleja y estética que la vida es. Pero ustedes se preguntarán hoy: porqué hablo de la vida si esta conferencia tendría que ocuparse de pensar la Humanidad, la crisis civilizatoria, la crisis ambiental? Porque lo Humano hoy, el humano que somos, tiene que volver a ser pensado en clave de la crisis ambiental, que es crisis de la vida y de lo vivo y que es expresión profunda y dolorosa de la crisis civilizatoria que ha venido desplegándose desde hace más de dos siglos. Las Humanidades que se habían ocupado de lo humano de lo humano, 
de la humanidad de la humanidad, es decir de aquello que permite al humano ser humano y de pensar la categoría, sin duda eurocéntrica, de Humanidad, deben volver a ser pensadas desde la crisis ambiental y, en ella, desde un pensamiento ambiental por fuera del eurocentrismo.

¿Qué es lo que hace al humano, humano? En clave del pensamiento metafísico que fundó la idea de que el hombre estaba por fuera de la naturaleza, lo que haría al humano humano, sería la razón, que según Descartes estaba hecha de una substancia diferente a la substancia de la que estaba hecha la naturaleza. La substancia de la razón era una substancia eidética, mientras que la substancia de la naturaleza era extensa, es decir, medible. El eidos humano sería tá mathema tá: experiencia anterior a cualquier experiencia. La medición, en cambio, sería la experimentación de la razón tá mathema tá sobre la naturaleza, que se dejaría medir por ser substancia extensa.

Por supuesto, las humanidades que se configuran en los siglos XVII y XVIII en Europa...el acento de lo humano llamado humanismo, que se despliega en estos dos siglos emerge de la escisión moderna entre sujeto y objeto; razón y naturaleza; cultura y naturaleza; sociedad y naturaleza.

Las ciencias humanas, las humanidades, que se configuran desde el siglo de la Ilustración, harán del hombre un ser metafísico cuyo máximo será el despliegue de la razón sobre la naturaleza: como dominio, en el siglo XVII, sujeción y control en el XVIII, explotación en el XIX, devastación en el XX, destrucción y desertización en el siglo que comienza. Este, nuestro siglo XXI, marcado por lo ambiental en todas sus maneras, discursos, adjetivos, prefijos y teleologías.

La escisión hombre - naturaleza en la Modernidad será entonces fundamental en la construcción de las Ciencias Sociales y Humanas, cuya preocupación será la exaltación del hombre como alfa y omega de todo saber, como origen y fin último de todo conocimiento, como única razón de toda existencia, como centro alrededor del cual gira todo, como semidiós ante el cual es necesario hincarse y reconocer en él la máxima creación, además hecha a imagen y semejanza de dios.

La razón Humana y todas sus creaciones están por encima de la naturaleza. La ciencia se ocupará de estudiar por separado la naturaleza y el hombre. Las ciencias naturales serán ciencias sin hombre y las ciencias sociales y humanas, ciencias sin naturaleza. La exaltación del hombre (como sujeto-razón), hará que ellas se dediquen a pensar y expresar al hombre como libre de las determinaciones de la naturaleza y a la humanidad como escindida de la naturaleza; como dominadora, calculadora, transformadora y destructora de la naturaleza. La 
naturaleza se reducirá a objeto. El control matemático, permitirá su mercantilización, la venta de la naturaleza, la explotación de la tierra, la destrucción de la trama compleja y maravillosa de la vida.

La vida que es póiesis, creación permanente, metamorfosis, tránsito, multiplicidad y singularidad se reducirá a mercancía controlada por la Biopolítica, la Geopolítica, la Anatomopolítica y la Genomopolítica. Emerge entonces la crisis de la vida. El humano que debería cuidar la vida, ahora la explota, vende, destruye y devasta en nombre del desarrollo. La crisis ambiental expresará entonces no una crisis de recursos naturales, sino y ante todo, una crisis civilizatoria; una crisis de la Humanidad europea, en palabras de Edmund Husserl; una crisis de la civilización occidental, en palabras de Augusto Angel.

Necesitamos un nuevo comienzo del pensar. Un giro profundo de lo Humano; una nueva filosofía, una concepción-otra del arte, las maneras de conocer, la técnica y en general, la cultura. Nuestra propuesta hoy es construir ese giro de lo humano en clave de la tierra, del cuerpo-tierra que somos. La tarea del pensamiento ambiental es disolver críticamente la escisión cultura - naturaleza, hombre naturaleza. El pensamiento ambiental sobre lo humano exige la reconciliación y la disolución del hombre con la naturaleza y del hombre en la naturaleza. Potentes expresiones artísticas nos permiten esta reconciliación, este giro ambiental de lo Humano. Ellas nos permitirán comprender en esta tarde, el pensamiento ambiental que está emergiendo en varios sitios de América.

La conexión entre vida y obra de arte se hace patente, porque el arte es vida y la vida sólo es posible como labor de arte. El Pensamiento Ambiental y el Arte tienen lugar en la sensibilidad, que es la manera como los cuerpos de la vida se configuran. La vida se hace cuerpo en el contacto. El cuerpo, todos los cuerpos son cuerpos gracias al otro; su realización está en el sentir y ser sentido. La exterioridad, el otro, lo otro, configuran la vida del cuerpo porque éste sólo es en tanto se disuelve en otro. Arte y Pensamiento Ambiental son entonces expansión de lo sensible. Son piel de la tierra, son tierra en pliegue. Una pedagogía de lo humano hoy, es una pedagogía en la piel de la piel. Pedagogía del sentir, del sentimiento, de la sensación, de la vida. Comprender el alfabeto de la naturaleza en su singularidad, es posible sí y sólo sí abandonamos la idea de lo humano como sujeto y reconfiguramos lo humano como emergencia de la naturaleza.

El arte permite esta reconfiguración. La experiencia estética hace que olvidemos la idea de explotar y dominar la naturaleza, porque permite comprender que somos naturaleza. Una vez sentida, la naturaleza se torna madre, lugar de origen, lugar de vida y muerte. Educar 
en el sentir es entonces comprender el alfabeto de la tierra: sus vocablos, sus susurros, su grito denso, profundo permanente y silencioso. Oler y palpar el humus de la tierra, es sentir lo humano deviene etimológicamente de la palabra humus: el nutrir y nutrir-se de la tierra. Eso es lo Humano. Pensar lo Humano en clave ambiental, es pensamiento que se siente en el pliegue del cuerpo; sentimiento que se piensa en el doblez del ser. El artista romántico lo siente, lo piensa, no es posible el humano escindido de la naturaleza. Esta Mujer en el Ocaso es de un lado la tensión que Kaspar David Friederich percibe entre una humanidad engreída por el saber científico-técnico y otros humanos que sólo son humanos en tanto se maravillan con la naturaleza, se asombran ante ella, la aman y quieren disolverse en ella. Ante la emergencia del sujeto trascendental dominando el universo, el asombro de la mujer en el ocaso, donde ella es el paisaje que siente.

La obra de arte nos permite comprender la tierra. Extraña, bella y estrecha relación, la obra de arte y la tierra están hechas de lo mismo. De este íntimo contacto emerge un pensamiento que piensa este contacto, que se sumerge en él para volver a emerger. Es un pensamiento ambiental; un geo-pensamiento, un pensamiento-tierra, un pensamiento-cuerpo, y un cuerpo-pensamiento. Es un cuerpo que solo es cuerpo pensando, y un pensamiento que solo es pensamiento sintiendo. “Lo que en mí siente, está pensando" . Sentir pensando, pensar sintiendo. Así al pensamiento ambiental también le adviene un sentimiento ambiental. Los dos humanos en la Aurora de Friederich, son humanos-otros. Humanos que sienten el paisaje, se sienten paisaje, son el paisaje. El giro ambiental de los estudios sobre lo humano consiste en ambientalizar el pensamiento sobre lo humano. Sentir que no es posible habitar poéticamente esta tierra, mientras haya control, mercantilización, devastación y destrucción de la vida. Como los dos humanos en la Aurora, lo humano solo es posible en la tierra.

La literatura, escribía Ángel Maya, es un lenguaje intermedio entre la filosofía y la realidad: "la literatura quiere atrapar la realidad en su esquivo fluir" , "no teoriza sobre las pasiones sino que las describe" , "no investiga el origen del paisaje, sino que lo recorre” .

La filosofía antes de la escisión entre en mundo de la metafísica y el mundo de las apariencias era un goce, un disfrute, que acontecía en el discurrir de la vida. La doxa y la episteme conectadas por el lenguaje de la literatura que era filosofía y la filosofía que era literatura, expresaban la posibilidad del goce pleno de la tierra. Pero la escisión platónica con su juego de luces y de sombras, desgarró el goce de la vida y colocó a los hombres en la frontera existente entre el mundo metafísico y el mundo de las apariencias. Sentir dejó de ser una manera del pensar y pensar dejó de ser una manera del sentir. "Sin embargo ya no fue 
NORUS - v3, n.3, jan-jun 2015.

posible regresar al jardín de las Hespérides”, ni recuperar el sentimiento terreno de Safo o Anacreonte; “ya no fue posible el apego alegre a la belleza sensible. Los dioses del Olimpo se negaron a regresar a la tierra y quedaron reducidos a una ostentosa decoración palaciega” , pero “permanecieron en la memoria de los hombres como un recuerdo imborrable de los goces perdidos y nunca completamente recuperados” .

“La tragedia de la cultura occidental quizás no haya sido todavía descifrada en su dolorosa realidad" (‥) “Es una cultura que en veinte siglos no ha logrado librase del peso de una conciencia pecadora” cuando el goce, el disfrute y el placer del cuerpo, de la vida, del sentir y ser sentido, permita momentos plenos en la existencia humana. La amputación del erotismo ha producido en la cultura un permanente dolor: el de la pérdida de la tierra y por tanto de lo humano, por ello es necesario desandar los pasos hasta ahora recorridos...

El pensamiento sobre lo humano, en clave de un geo-pensamiento, de un pensamiento que emerge del reconocimiento de lo humano como humus que permite comprender la lengua de la tierra y comprender lo humano como tierra, despliegan otra manera del sentir.

Cada tarde y noche de miércoles, cada noche de lunes, cada mañana de jueves, cada tarde de viernes...cada día o noche con nuestros discípulos, con nuestras comunidades de vida, se re-funda lo fundado, se re-crea lo creado, se de-construye y re-construye lo construido, y lo que no ha sido fundado, ni creado ni construido. Ante “El grito" (1893) del pintor noruego Edvard Munch: silencio trágico, profundo. Cuando habla Munch, cuando relata que sintió el grito profundo, infinito, doloroso y grave de la naturaleza, cuando enfatiza que quien grita en su obra es la naturaleza en él, hay una comprensión de otro orden. Una metamorfosis de la mente, del pensamiento, del sentimiento. Munch, el artista, se disuelve en la naturaleza para comprenderla. Escucha su grito y se pinta, lo pinta. No es un hombre gritando, es la naturaleza que grita en el hombre que es naturaleza.

Cada pincelada de esta obra es un hilo del tejido denso de la piel de la tierra. Cielo, tierra, puente, fiordo, hombres, todos, están hechos del mismo material. El Grito de la naturaleza se expresa en la piel de lo humano, gracias a las pinceladas de Munch en su óleo de 1893. Autorretrato, retrato de un tiempo miserable que ha devenido crisis ambiental como crisis civilizatoria, el Grito emerge de los confines de la tierra, de las profundidades del mar, de cada cultura devastada, de cada explosión de la tierra producida por la insaciable voracidad del desarrollo. 
Como el humano Munch, la tierra grita en esta fotografía. ¿Cuánto dolor y destrucción están detrás de esta inmensa boca, abierta violentamente por el mundo de la industria minera Murowa Diamonds? Incontable e innarrable es el dolor de los seres vivos, de la tierra devastada. La boca gritando pintada por Munch, ha devenido esta boca de la tierra.

El fotógrafo Edward Burtynsky se sumerge en este paisaje del desarrollo para mostrar la otra cara, la oculta, la del grito silencioso de una tierra que ya no soporta el despilfarro propio del esquizofrénico humanismo. El fotógrafo brasilero Sebastiao Salgado es el grito de noventa mil "garimpeiros” (trabajadores de las minas de oro en Brasil), que en la década de los 80 s, fueron esclavizados por la Industria Minera Vale.

El grito de la tierra es el grito del hombre explotado explotando a su propia madre. ¿ Existe algo peor que ser explotado explotando a la madre? ¿ De qué se están ocupando las ciencias sociales, las ciencias humanas, las humanidades hoy? ¿ Qué estamos pensando cuando humanistas que hemos sido, creemos que la explotación insaciable de la tierra es la tarea del hombre?

En la voz del artista, la tierra grita. La tierra Abya Yala: tierra en florecimiento, tierra generosa, la tierra donde sopla el viento: Amerrique, la gente de la Tierra: Mapuche. La Tierra del Sumakawsay: Buen Vivir, es pintada por Oswaldo Guayasamín en su momento de dolor supremo.

Tres Gritos pintados por el maestro, en 1983, expresan no solo el grito de la tierra, sino el grito de la vida, el grito del hombre - latinoamericano -... ese otro, hecho del mismo material que las plantas y los animales, pero esclavizado, reducido, vejado, dominado, explotado como la tierra a la que pertenece, pero usurpada por Europa en tiempos de la expansión imperial y ahora, de la expansión post-colonial.

Cada Grito es solo una expresión del dolor sostenido de quinientos años de explotación, donde tuvimos que renunciar a ser el nosotros-tierra que siempre fuimos, para ser los sin-tierra que hemos sido. No porque pensáramos que la tierra fuera de nosotros, sino porque siempre hemos sabido que nuestro origen es la tierra, como madre, Pachamama, Mapuche, Abyayala. Que somos cuerpos-tierra y que pertenecemos a ella. Las imágenes arquetípicas ambientales comienzan a transformar los imaginarios, siempre colectivos que mueven la cultura, que hacen de cada cultura, singular, única, diversa.

Comprender estas obras de arte con nuestros estudiantes, con las comunidades de vida, transforma nuestra condición humana, nuestras maneras de habitar la tierra, porque el arte reúne los tiempos y los espacios en geopoéticas. Propone miradas distintas, miradas-otras que 
reencantan el mundo, que recuerdan lo que somos y no lo que hemos querido ser. Cuando miramos la América Invertida de Joaquin Torres García (1943) o la obra Raices, de Frida Kalho (1943), todo cambia en nuestra concepción de lo humano. Ya nos somos los mismos. Devenimos otros. Otros en otra Tierra que es la nuestra olvidada. Otros hechos de tierra, tejidos en la tierra.

¿Quien no construye-habita-piensa distinto luego de comprender lo que estas obras de arte nos narran? La transformación de nuestro sentir es urgente hoy, cuando el ethos del habitar humano se orienta a la devastación de la tierra, en la voracidad sin límites del desarrollo. El pensamiento estético de los artistas es un pensamiento-piel que emerge del cuerpo.

La razón occidental moderna se configuró en clave de una finalidad: la del dominio de la naturaleza para el desarrollo de la sociedad. El concepto de naturaleza necesario para ese dominio fue el mecanicista, donde la naturaleza se consideró divida en partes y éstas en objetos claros y distintos dispuestos para la investigación científica, el control bio-geopolítico y la manipulación tecnológica. El concepto de sociedad necesario para estos fines fue el de una sociedad meta-física, es decir, una sociedad que estaba por “encima” y “separada” de la naturaleza. Una sociedad cuyo proyecto único se consideró universal. A este proyecto se llamó filosóficamente “modernidad” y económicamente “desarrollo" .

Los dos nombres fueron siempre sinónimos, pero la Modernidad se desplegó en la razón universal presente en la ciencia, la política, la ética y la estética, mientras que el Desarrollo se desplegó en la tecnología, la economía y el mercado. Los dos siempre han estado juntos, pues se necesitan para poderse realizar. La educación, como principal forma de configurar los cuerpos, la cultura, la naturaleza, las imágenes de dios, el pensamiento, la ética y la política, se puso al servicio de los paradigmas de la Modernidad, para desplegarlos, realizarlos y expandirlos. La educación “ambiental”, necesita de otros lugares de enunciación, de otras maneras de pensar y pensarse, porque los paradigmas de la modernidad son anti-ambientales, en tanto emergen de la escisión entre hombre y naturaleza y procuran el dominio de la razón sobre la naturaleza.

Lo estético, el sentir, la piel, el cuerpo, dejan de ser “triviales” : a esto fueron y siguen siendo reducidos por las lógicas del mercado global y la publicidad. El pensamiento ambiental encuentra en lo estético, en el sentir, en la piel y en el cuerpo, el lugar desde el cual es posible el giro ambiental del pensamiento humanístico y social. Encuentra que el arte permite la realización de esta tarea, porque su poder transformador del sentir es infinito. El 
pensamiento ambiental sabe que en el sentir está la clave del ethos. La ética moderna se redujo a máximas universales; el ethos ambiental se pregunta por la singularidad de la tierra que se habita, habita y es habitada.

El conocimiento emergente de la potente relación entre arte y ambiente, no se reduce a lo estadístico, o a la fría cuantificación de los " recursos naturales" . Como estos “Dos hombres frente al mar” (1817) del pintor romántico Kaspar David Friederich, que no solo miran el mar, sino que se pierden en él para encontrarse, el conocimiento permitirá asombrarse ante un rayo de sol, disolverse en la naturaleza, conmoverse ante la belleza de las plantas, los animales, la vida. En palabras del poeta Hölderlin (1799):

\begin{abstract}
¡ Pero tú brillas todavía, sol del cielo! ¡ Tú verdeas aun, sagrada tierra! Todavía van los ríos a dar en la mar y los árboles umbrosos susurran al mediodía. El placentero canto de la primavera acuna mis mortales pensamientos. La plenitud del mundo infinitamente vivo nutre y sacia con embriaguez mi indigente ser. i Feliz naturaleza! No sé lo que me pasa cuando alzo los ojos ante tu belleza, pero en las lágrimas que lloro ante ti, la bienamada de las bienamadas, hay toda la alegría del cielo. Todo mi ser calla y escucha cuando las dulces ondas del aire juegan en torno de mi pecho. Perdido en el inmenso azul, levanto a menudo los ojos al Éter y los inclino hacia el sagrado mar, y es como si un espíritu familiar me abriera los brazos, como si me disolviera el dolor de la soledad en la vida de la divinidad. Ser uno con todo, esa es la vida de la divinidad, ese es el cielo del hombre. i Ser uno con todo lo viviente!, volver, en un feliz olvido de sí mismo, al todo de la naturaleza, esa es la cima de los pensamientos y alegrías, esta es la sagrada cumbre de la montaña, el lugar del reposo eterno donde el mediodía pierde su calor sofocante y el trueno su voz, y el hirviente mar se asemeja a los trigales ondulantes. (HÖLDERLIN, F. Hiperión o El eremita en Grecia, 1976, p.7).
\end{abstract}

Sólo los poetas. Sólo ellos hablan la lengua de la tierra. El humano, lo humano deviene poesía. Esto no exige hacer música, pintar cuadros o escribir poesía. Esto exige que la educación en lo humano, pase de enseñar un mundo dispuesto para el cálculo, la mercantilizaión y la explotación: precisio mundi a construir con nuestros estudiantes, con nuestras comunidades de vida, la precultio mundi: un mundo donde el cuidado, el asombro, la admiración y el afecto por la vida, configuren el curriculum escolar.

El científico Manfred Eigen, premio nóbel de Química en 1969, advirtió en su conferencia de recepción del premio nóbel:

\footnotetext{
"Nos encontramos en la última década de este siglo; ninguna centuria anterior ha tenido un efecto tan profundo sobre la vida humana. Puede que ninguna otra centuria haya generado tal grado de recelo y temor, hasta el punto de que han arraigado en la conciencia humana. Nos hemos vuelto desconfiados. Hoy en día, cuando se da a conocer un descubrimiento la primera pregunta ya no es, como antes, qué servicio prestará a la humanidad, sino qué perjuicios causará...”
} 
NORUS - v3, n.3, jan-jun 2015.

Unos años antes, la filósofa Hanna Arendt, en su obra, especialmente en La Condición Humana, advertía sobre la urgencia de volver a pensar lo Humano, aquello que nos daba especificidad. La Segunda Guerra Mundial había terminado con la bomba atómica lanzada por los Estados Unidos sobre Hiroshima y Nagasaki. Los más refinados desarrollos de la ciencia y la tecnología se habían colocado al servicio de la destrucción de la vida. Era necesario volver a pensar lo ya pensado. Era urgente, recordar que la Crisis de las Ciencias anunciada por Edmund Husserl en 1935, que se expresaba en ese momento con rigor, no era una crisis de método, sino de sentido. Y el sentido no era solamente tener una dirección, sino la posibilidad negada a partir del lenguaje positivista del sentir y ser sentidos, del sentimiento, del cuerpo, de la sensibilidad negada por la precisio mundi.

La transformación de los símbolos de la cultura que propone Augusto Angel Maya, será entonces la recuperación, econstrucción, configuración de la precultio mundi, reencantamiento del mundo que permite sentir y ser sentidos, sentirnos tierra, que es agua, viento, fuego y cielo. Así, vamos de-construyendo el sistema lingüístico que se han configurado desde una precisio mundi, para nombrar la naturaleza, la vida: “recurso suelo” , “ recurso agua ”, recurso aire”, recurso fauna ”, “ recurso flora ”, “ cuentas ambientales”, “servicios ambientales” y vamos construyendo de la mano de René Magritte en su obra “El Seductor” (1953), un sentimiento-pensamiento ambiental que nos seduce: estamos hechos del lugar que habitamos, como el barco está hecho de agua.

Introducir el Pensamiento Ambiental en las Humanidades es reconfigurar la sensibilidad: el sentir y ser sentidos, los afectos como afectaciones. Por ello es urgente desencantar el mundo de la Modernidad, para reencantar el mundo de la vida. La obra de arte, la literatura, la poesía, la filosofía, la música, permiten esto, no como herramientas didácticas sino como expresión de la tierra en la piel de lo humano. Si queremos educar en lo ambiental, tenemos que comprender que sólo habitamos respetuosamente y bellamente esta tierra si la habitamos en labor de arte, como nos lo recuerda el filósofo español Jose Luis Pardo Torío; poéticamente, como nos lo pregunta Heidegger y lo propone Edgar Morin. En reencantamiento del mundo, que ha sido nuestro trayecto siempre abierto a la palabra de la tierra.

Transcrição realizada pelos estudantes:

Pedro Henrique Conte

Jimena González Ruiz 